\title{
Integrating postpartum contraceptive counseling and IUD insertion services into maternity care in Nepal: results from stepped-wedge randomized controlled trial
}

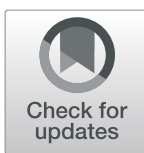

Elina Pradhan ${ }^{1}$, David Canning ${ }^{2}$, Iqbal H. Shah ${ }^{2 *}$, Mahesh Puri ${ }^{3}$, Erin Pearson ${ }^{4}, K_{\text {Kusum Thapa }}{ }^{5}$, Lata Bajracharya ${ }^{5}$, Manju Maharjan ${ }^{3}$, Dev C. Maharjan ${ }^{3}$, Lata Bajracharya ${ }^{5}$, Ganga Shakya ${ }^{5}$ and Pushpa Chaudhary ${ }^{6}$

\begin{abstract}
Background: In Nepal, 54\% of women have an unmet need for family planning within the 2 years following a birth. Provision of a long-acting and reversible contraceptive method at the time of birth in health facilities could improve access to postpartum family planning for women who want to space or limit their births. This paper examines the impact of an intervention that introduced postpartum contraceptive counseling in antenatal care and immediate postpartum intra-uterine device (PPIUD) insertion services following institutional delivery, with the intent to eventually integrate PPIUD counseling and insertion services as part of routine maternity care in Nepal.

Methods: This study took place in six large tertiary hospitals. All women who gave birth in these hospitals in the 18-month period between September 2015 and March 2017 were asked to participate. A total of 75,587 women ( $99.6 \%$ consent rate) gave consent to be interviewed while in postnatal ward after delivery and before discharge from hospital. We use a stepped-wedge cluster randomized design with randomization of the intervention timing at the hospital level. The baseline data collection began prior to the intervention in all hospitals and the intervention was introduced into the hospitals in two steps, with first group of three hospitals implementing the intervention 3 months after the baseline had begun, and second group of three hospitals implementing the intervention 9 months after the baseline had begun. We estimate the overall effect using a linear regression with a wild bootstrap to estimate valid standard errors given the cluster randomized design. We also estimate the effect of being counseled on PPIUD uptake.

Results: Our Intent-to-Treat analysis shows that being exposed to the intervention increased PPIUD counseling among women by 25 percentage points (pp) [95\% Cl: 14-40 pp], and PPIUD uptake by four percentage points [95\% Cl: 3-6 pp]. Our adherence-adjusted estimate shows that, on average, being counseled due to the intervention increased PPIUD uptake by about 17 percentage points [95\% Cl: 14-40 pp].
\end{abstract}

Conclusions: The intervention increased PPIUD counseling rates and PPIUD uptake among women in the six study hospitals. If counseling had covered all women in the sample, PPIUD uptake would have been higher. Our results suggest that providing high quality counseling and insertion services generates higher demand for PPIUD services and could reduce unmet need.

Trial registration: Trial registered on March 11, 2016 with ClinicalTrials.gov, NCT02718222.

Keywords: Nepal, Postpartum contraception, Counseling, IUD uptake, Impact evaluation

\footnotetext{
* Correspondence: ishah@hsph.harvard.edu

${ }^{2}$ Department of Global Health and Population, Harvard T. H. Chan School of

Public Health, 665 Huntington Avenue, Boston, MA 02115, USA

Full list of author information is available at the end of the article
}

(c) The Author(s). 2019 Open Access This article is distributed under the terms of the Creative Commons Attribution 4.0 International License (http://creativecommons.org/licenses/by/4.0/), which permits unrestricted use, distribution, and reproduction in any medium, provided you give appropriate credit to the original author(s) and the source, provide a link to the Creative Commons license, and indicate if changes were made. The Creative Commons Public Domain Dedication waiver (http://creativecommons.org/publicdomain/zero/1.0/) applies to the data made available in this article, unless otherwise stated. 


\section{Plain English summary}

Intra-uterine contraceptive device (IUD) inserted soon after delivery provides long-term protection against unintended pregnancy and can be a particularly suitable option for women who visit hospitals for delivery, but may not revisit because of distance or cost of transportation. Therefore, an intervention launched in Nepal: (1) counseled women on family planning methods after delivery during their antenatal care visits, (2) trained medical staff to insert IUD following delivery, referred as the postpartum period, and (3) thus aimed to integrate postpartum family planning, and postpartum IUD (PPIUD) services into regular maternity services. We examine the impact of this intervention on contraceptive counseling and PPIUD uptake. All women who gave birth in six tertiary hospitals in the 18-month period between September 2015 and March 2017 were asked to participate and 75,587 women who agreed were interviewed after delivery and before discharge from hospital. Baseline data were collected for 3 months in first group of hospitals after which intervention was launched in these hospitals, and the second group of hospitals had 9 months of baseline data collection before the intervention was launched. Our analysis shows that the intervention increased PPIUD counseling by 25 percentage points. It also increased PPIUD uptake by four percentage points. If all women were counseled by the program, PPIUD uptake would have increased by 17 percentage points. Our results suggest that providing high quality counseling and insertion services generates higher demand for PPIUD services and could help women meet their fertility desires to space or limit childbearing in Nepal and in similar contexts.

\section{Background}

Increased access to family planning in low-income countries is linked to reduced maternal morbidity and mortality, and reduced infant and child morbidity and mortality [1-4]. The International Conference on Population and Development (ICPD) Programme of Action that was adopted by 179 UN member states in 1994 advocated the right to plan a family size and birth spacing as central reasons for expanding family planning access $[5,6]$. Globally, although there has been an impressive increase in access to family planning in the last few decades [7], much work remains in ensuring the ICPD goals of provision of universal access to reproductive health services, including family planning.

In Nepal, contraceptive prevalence among married women aged $15-49$ years increased from 19 to $53 \%$ between 1990 and 2016, and while the unmet need for family planning decreased from 34 to $24 \%$ over the same period [7, 8], concerted efforts are still needed to increase access, especially in the postpartum period. Only
$9 \%$ of the women are counseled on family planning during their postpartum period in Nepal, and $54 \%$ have an unmet need for family planning within the 2 years following a birth [8]. Despite the World Health Organization's (WHO) recommendation of waiting at least 2 years after a live birth before attempting the next pregnancy to reduce the risk of adverse maternal, perinatal and infant outcomes [9], 25\% of women in Nepal become pregnant within 24 months postpartum [10]. Hence, there is a gap in postpartum family planning (PPFP) counseling and uptake in Nepal, and with rising coverage of antenatal care (ANC) and institutional delivery, an opportunity to understand whether an attempt to integrate postpartum family planning services into maternity care would improve uptake of postpartum family planning in Nepal.

Global rates of antenatal care visits and skilled birth attendance have increased in the past decades [11], and Nepal is no exception. In the period 2014-2016, 84\% of women who gave birth had at least one antenatal care visit, and $57 \%$ of all births took place in a health facility (skilled birth attendance was 58\%) [8]. This is a sharp increase from 2001 when only $9 \%$ of the women gave birth in a health facility in Nepal [12].

For many women in Nepal who have limited access to healthcare services, antenatal visits, facility delivery, and postnatal visits present important opportunities for counseling and provision of family planning services, which may enable them to meet their birth spacing or limiting desires by offering a long-acting and reversible method [13].

Offering family planning counseling during antenatal visits, and provision of an IUD in immediate postpartum period (PPIUD) to women undertaking delivery in a health facility can be an effective way of reducing the unmet need for family planning in the postpartum period. IUD is a safe, effective, long-lasting and reversible method of contraception [14, 15]. PPIUD, inserted in the immediate postpartum period: (1) is associated with fewer side effects and discomfort during insertion compared to an interval IUD (inserted after more than 4 weeks postpartum), (2) has higher continuation rates at 6 months [16], and (3) is recommended by the WHO as safe for use by all women, including breastfeeding women or women who are HIV positive [15].

Previously published studies on the impact of provision of PPIUD services have been based on cross-sectional and/or program data. One such recent study was a large multi-country implementation program that incorporated provision of PPIUD services into routine maternity care in six countries-Guinea, India, Ethiopia, the Philippines, Rwanda and Pakistan. This study showed that, among women counseled, between 2.3 to $5.8 \%$ chose PPIUD, and a median of about $2 \%$ of all women who gave birth in the study facilities took up PPIUD [13]. 
We believe this is the first study that aims to investigate the causal impact of provision of PPFP counseling and PPIUD insertion services as a part of routine maternity care. We use a randomized stepped-wedge cluster design to evaluate the causal impact of the provision of these services by employing a hospital level randomized rollout with hospitals adopting the intervention in two waves that were 6 months apart. This allows us to estimate the impact of the intervention while controlling for underlying trends in PPIUD use. The aim of this paper is to estimate the impact of the intervention on PPIUD counseling and uptake using data collected from women after delivery and before discharge from hospital-by measuring the intervention uptake, we hope to understand the feasibility of integrating PPFP counseling and PPIUD insertion services into facility-based antenatal and delivery care in Nepal.

The intervention aimed to change provider knowledge and behavior by training them on postpartum family planning, including PPIUD counseling and insertion techniques, and to change patient knowledge and behavior through counseling by the trained providers. However, human resource constraints in health facilities could attenuate the impact of the training program on PPIUD counseling and uptake [17]. Since not all women who delivered after the intervention began were counseled, we also provide adherence-adjusted estimates of the effect of being counseled on PPIUD uptake. This gives the causal effect of being counseled due to the intervention on PPIUD uptake, removing any selection bias of targeting particular women. Moreover, it has been shown that the quality of PPIUD counseling can affect uptake of PPIUD [18]. We therefore estimate how variations in the quality of counseling affected PPIUD uptake.

\section{Methods}

This trial is registered with ClinicalTrials.gov with ID: NCT02718222. Detailed study protocol has been published elsewhere [19]. However, main features of the study are described below.

\section{Study population}

This study took place in six tertiary hospitals: Bharatpur Hospital, Bheri Zonal Hospital, BP Koirala Institute of Health Sciences (BPKIHS), Koshi Zonal Hospital, Lumbini Zonal Hospital and Western Regional Hospital. Four of the study hospitals are in Terai region, and two (BPKIHS and Western Regional Hospital) in Hill region. Figure 1 shows a map with the location of these hospitals. The inclusion criteria for hospital sites in this study were: (i) high volume of obstetric caseloads (>6000 a year), (ii) large catchment area, and (iii) not located in the capital city, with the intent to ascertain if the intervention

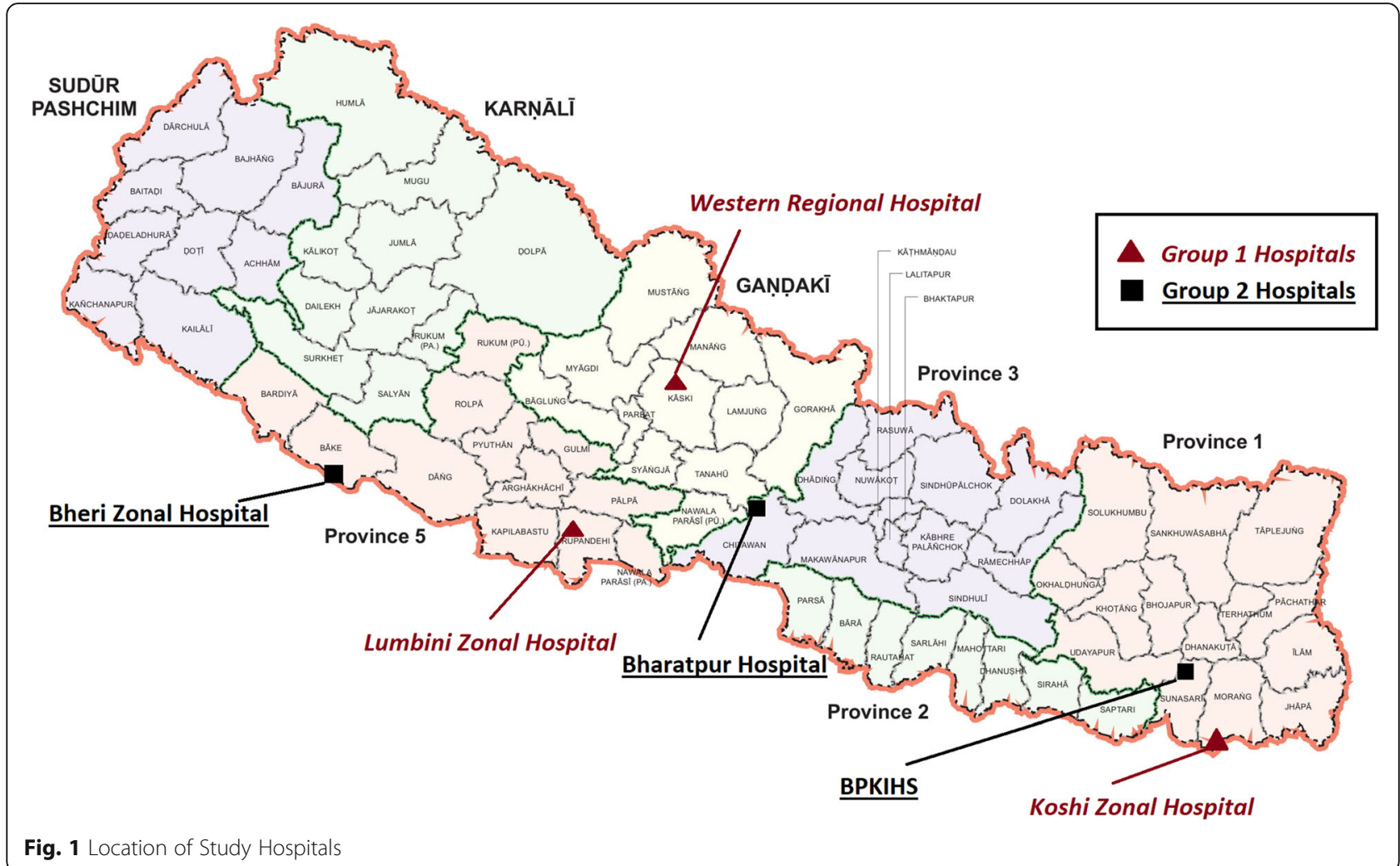


could successfully build capacity in hospitals outside of Kathmandu valley. All women who gave birth in these six hospitals in the 18-month period between 8th September 2015 and 8th March 2017 were eligible to be included in the study sample unless their primary residence was outside of Nepal. Out of a total of 75,897 women eligible to enroll in the research study during the enrollment period, 75,587 (99.6\%) consented to be interviewed, and interviews were conducted after delivery but prior to discharge from hospital. The full sample used in this study constitutes of 75,566 women with complete information among those who consented to participate in the study.

Ethical approval for this study was obtained through Nepal Health Research Council, and the Harvard T. H Chan School of Public Health Office of Human Research Administration granted exempt status to the study as Harvard only received de-identified data.

\section{Study design}

We use a stepped-wedge cluster randomized design. All hospitals had at least 3 months of baseline data collection, and the intervention was introduced into the hospitals in two steps. Six hospitals were placed in pairs matched by geography (Hill versus Terai), and then by the annual obstetric caseload. Each pair was randomized into either group 1 (early intervention) or group 2 (late intervention). The three pairs were: (i) Western Regional and BPKIHS, (ii) Lumbini Zonal and Bharatpur, and (iii) Koshi Zonal and Bheri Zonal. The three hospitals in Group 1 (Lumbini Zonal, Koshi Zonal and Western Regional) were scheduled to start their intervention in the fourth month after 3-month baseline data collection, and Group 2 hospitals (BPKIHS, Bharatpur and Bheri Zonal) were scheduled to start their intervention in the tenth month after 9-month baseline data collection.
Figure 2 shows the baseline and intervention period in each of the six hospitals. All hospital baseline data collection began on September 8, 2015. Actual timing of the start of the intervention by hospitals in each group varied slightly due to the need for trainers to move between hospitals to provide training. Group 1 hospitals began the intervention a few weeks apart from each other, in December 2015, whereas the intervention in Group 2 began in the summer of 2016.

\section{The intervention}

The intervention was designed and implemented by International Federation of Gynecology and Obstetrics (FIGO) in partnership with Nepal Society of Obstetricians and Gynaecologists (NESOG). FIGO and NESOG designed the intervention in adherence with the national health systems and training guidelines and in coordination with the Ministry of Health and Population in Nepal to ensure sustainability of any future scale-up of the program.

The intervention comprised of: (1) informational workshops for female community health volunteers and general hospital staff, (2) training of maternity care providers in postpartum family planning counseling, PPIUD insertion techniques and complication management, (3) provision of postpartum family planning leaflets to be distributed during counseling, (4) an information wall chart and video to be displayed in the hospital waiting area, (5) provision of Kelley's forceps for vaginal PPIUD insertion and IUDs to be provided to hospitals by the Ministry of Health and Population (IUDs were free at point-of-care to women), (6) one service provider in each hospital being designated as facility coordinator for the program, and (7) regular monitoring of counseling and insertion data by NESOG and FIGO.

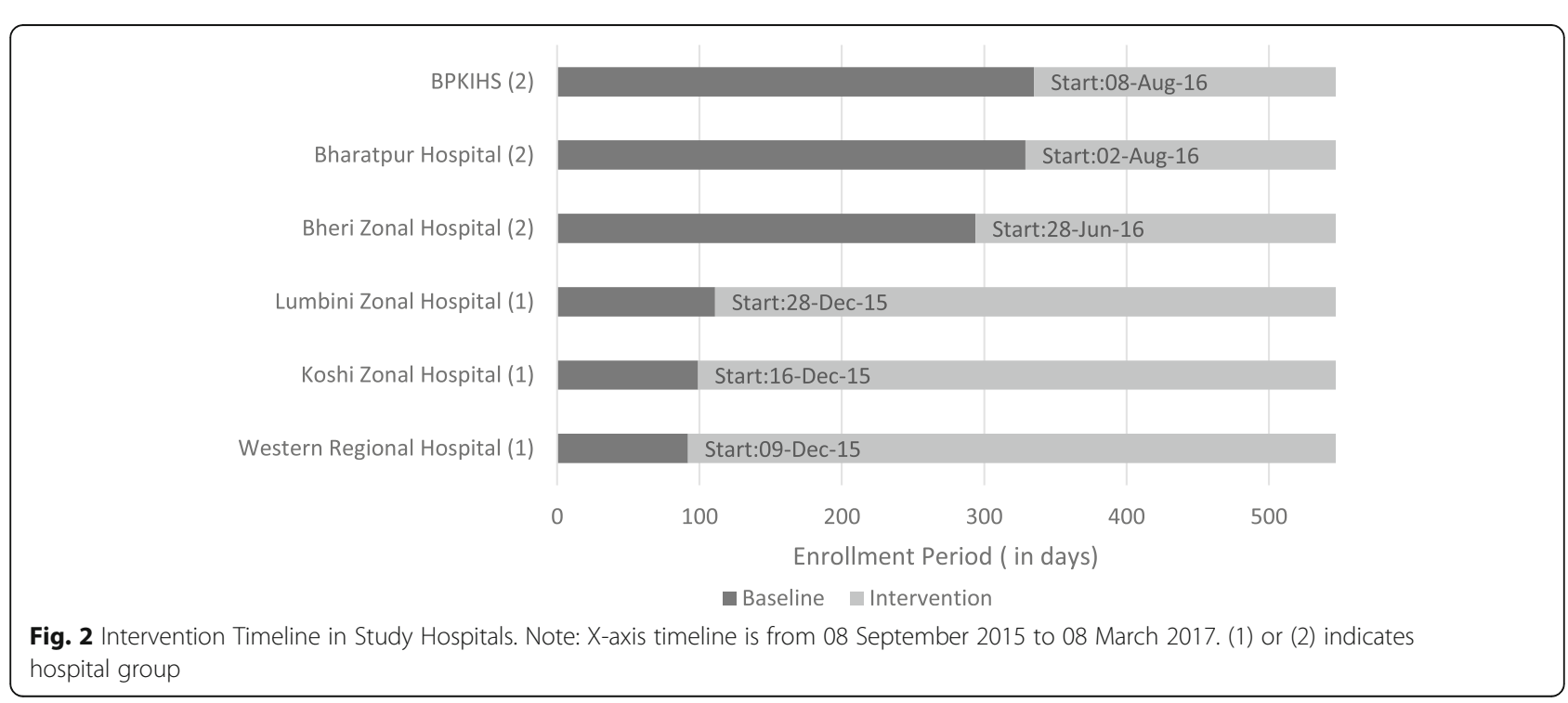




\section{Provider training}

Health professionals in the study hospitals who provide obstetric services-senior and junior doctors, nurses and midwives-were trained to provide postpartum family planning counseling services during antenatal visits, and to undertake PPIUD insertions. Each training workshop was 3 days long with six sessions, which included techniques in providing counseling services along with lectures, videos, practice IUD insertion sessions in MAMA-U mannequin models for vaginal and intra-caesarian procedures, and discussion of infection prevention, side-effects and complication management. Pre-training and mid-training knowledge assessments were also conducted along with role plays and group discussions to facilitate the training.

The providers were also trained to utilize postpartum family planning leaflets during counseling. These leaflets contain information about benefits of birth spacing, and information on different contraceptives, with guidelines on when to begin using them postpartum.

\section{Counseling and consent for insertion, and intervention inclusion criteria}

If a woman in the study was counseled on PPIUD, she could have been counseled either during her antenatal visit if she visited the hospital for antenatal care (ANC), or during her postnatal care (PNC) in a ward after delivery, or in antenatal wards if she arrived early for the birth and was not in active labor. She could also be counseled both during ANC and after admission to the hospital for delivery.

If women chose to have a PPIUD inserted, consent for insertion was taken at the point of choice (either at ANC or PNC), and confirmed and noted in maternity records immediately before the insertion process. For literate women, the consent was in written form, and thumb print was taken if women were illiterate. Though the consent form was in Nepali, women were explained the process and content of the consent form in their own language by providers. Note that IUDs are provided for free at point-of-care based on national reproductive health policy guidelines, and the IUDs used in the intervention sites were non-hormonal IUDs that last 12 years.

In terms of the intervention inclusion criteria, all pregnant women who visited the hospital for antenatal counseling or delivery services (vaginal or caesarean section) were eligible for PPFP counseling services, and all those who consented to PPIUD were eligible for IUD insertion in the immediate postpartum period.

\section{Data collection and composition of the questionnaire}

Enumerators posted in the hospitals interviewed women in the postnatal wards using structured questionnaires and the data were recorded electronically on hand-held tablets. The study questionnaire included questions about women's socio-demographic background, birth history, ANC visits, previous contraceptive use, any family planning and PPIUD counseling received during the antenatal or postnatal period, their satisfaction with these counseling services, uptake of PPIUD, and future fertility desires.

\section{Outcomes of interest and key treatment variable}

PPIUD counseling is a binary variable that indicates whether the woman reported receiving counseling for PPIUD either during ANC or after admission to the hospital for delivery. PPIUD uptake is also defined as an indicator variable for women who chose to accept insertion of a PPIUD. There were 27 women in our study who choose to accept PPIUD as postpartum contraception but did not receive a PPIUD because of complications during delivery and/or insertion. These women are defined as having chosen PPIUD because we intend to measure demand for PPIUD as a result of the intervention. Our key "treatment" variable is exposure to the intervention defined as delivering in a hospital after the start of the intervention as set out in Fig. 2.

\section{Analytic strategy}

Our intention-to-treat analysis (ITT) estimates the impact of the intervention on PPIUD counseling and PPIUD uptake. This impact was analyzed using a linear regression explaining the outcome (whether counseled on PPIUD and whether PPIUD was requested) with exposure to the intervention controlling for hospital fixed effects and month fixed effects to adjust for differences between hospitals and any underlying time trends. The differential timing of the intervention across hospitals allows us to identify the effect of the intervention separately from pure time effects. We provide estimates with just these hospital-level and time dummy explanatory variables, and with additional controls for the background characteristics of the women.

While the outcome variable is binary, we have a fully saturated model with discrete explanatory variables where every individual is in one of a finite number of strata; in this case, the prediction of the outcome given by the linear probability model is simply the average outcome for the stratum, and hence is a well-specified model for the binary outcome of PPIUD uptake. We can therefore estimate the intention-to-treat effect using a simple linear regression and the treatment effect is simply the difference in outcomes between the treatment and control groups [20].

Equation 1 below represents our basic ITT model, where the dependent variable $y_{i h t}$ is a dummy variable indicating PPIUD counseling received, or PPIUD uptake, by woman i who gave birth in hospital $\mathrm{h}$, on day $\mathrm{t}$. The main explanatory variable of interest is Post $t_{h t}$ which is an indicator variable that takes the value one in hospital $h$ on day $t$ after the start of the intervention and zero 
before the start of the intervention. The set of $d_{h}$ variables represents hospital fixed effects for hospitals (h) 1 through 5, with hospital 0 as reference. The set of $\tau_{m}$ variables represent month fixed-effects dummies for months 1 through 17 of the study with month 0 as reference. The $X_{i}$ represents a vector of variables representing the characteristics of woman i. We report results with (1) only the hospital, and time fixed effects and intervention effect, and (2) additional results where we also include these additional woman level variables.

Our regression is therefore:

$$
\begin{aligned}
y_{i h t}= & \alpha+\beta \text { Post }_{h t}+\sum_{h=1}^{5} d_{h}+\sum_{m=1}^{17} \tau_{m}+\gamma X_{i} \\
& +\epsilon_{i h t}
\end{aligned}
$$

Our primary interest is in the coefficient $\beta$ which is the effect of the intervention. However, not all women in the intervention hospitals were counseled. Women may not have visited the study hospitals for antenatal care, receiving care at local clinics nearer their homes, and therefore may not have been exposed to the intervention. We therefore also calculate an adherence-adjusted effect of the intervention on PPIUD uptake, or the impact of being counseled due to the intervention on accepting PPIUD, calculated using an instrumental variable approach [21].

Outcomes for women who visit the same hospital are likely to be correlated with each other due to unobserved hospital level variables. Hence, inference needs to be corrected for the potential correlation in the error term across women in the same hospital. Since we only have six hospitals, or six clusters, in our study, the standard cluster robust variance estimator based on a large number of clusters may be invalid [22]. We use the wild cluster bootstrap method with six-point bootstrap weight distribution to estimate the statistical significance of the effect size for all models. This approach has been shown to have good properties with six clusters [23-25].

We also present results from a descriptive analysis on how the quality of counseling affects PPIUD uptake among women who were counseled. We look at how the provision of a PPIUD information leaflet, the opportunity to ask questions, and women's knowledge of benefits or disadvantages of PPIUD, are related to the likelihood of accepting PPIUD.

Stata MP version 14.2 was used to perform all analyses (StataCorp LLC, College Station TX, USA).

\section{Results}

Table 1 reports the descriptive statistics of the women level covariates used in the analysis. Column 1 shows the mean of each variable for the full sample of 75,566 women. Columns 2 and 3 show the mean of each variable for the Group 1 and Group 2 hospitals during the first 3 months of data collection, and before the intervention began in either group. With individual-level randomization of the intervention, we would expect the means of these covariates to be equal. Because we randomized at the hospital-level, and there are few hospitals, there may be systematic differences in the two populations. Column 4 reports a test of the hypothesis that the two groups of hospitals have the same mean characteristics for women during the pre-intervention period using the wild bootstrap method. We find that Group 2 hospitals tended to have women who had longer travel times to reach the hospital. However, other covariates appear to be balanced across the two groups of hospitals.

Figure 3 shows the trends in PPIUD counseling rates in the six hospitals. During the baseline period, all hospitals had very low counseling rates and in all hospitals, there was a clear rise in counseling rates immediately after the intervention started. There is also some variability in counseling rates across the hospitals in the same group. Rates in Western Regional hospital were generally higher compared to the other hospitals. The highest monthly counseling rate achieved during the intervention period varied from 29 to $67 \%$ across the six study hospitals.

The counseling on any method of family planning also increased (Fig. 4) following the intervention. Overall, counseling on any method increased by 23 percentage points (pp) [CI: 5.3-41.0 pp] following the intervention compared to the pre-intervention period.

Table 2 shows the timing of PPIUD counseling, and selected measures of counseling quality. Around 39\% of women were counseled in the antenatal period; $43 \%$ were counseled only after admission for delivery; and $18 \%$ were counseled both before and after admission. Among women who were counseled, only $50 \%$ reported having given an opportunity to ask questions during counseling sessions, and 58\% reported receiving the postpartum family planning information leaflet. We asked women to recall benefits and some disadvantages of PPIUD and interviewers checked these responses against a list of benefits and disadvantages the counselors were trained to discuss with women. Among those counseled, $52 \%$ could recall only benefits of PPIUD, 23\% could recall at least one benefit and one disadvantage, and $24 \%$ could not recall any benefits or disadvantages of the method, or could recall only disadvantages.

Figure 5 shows results for the uptake of PPIUD, with very little uptake in any hospital during the baseline and evidence of uptake starting immediately after the intervention. There is high month-to-month variability with peaks and troughs in PPIUD uptake. However, the rise in PPIUD uptake is more pronounced after the training 
Table 1 Frequency and proportion of women in the first 3 months baseline period, by background and hospital group

\begin{tabular}{|c|c|c|c|c|c|}
\hline & \multirow[t]{4}{*}{ Full Sample } & \multicolumn{4}{|c|}{ First three months } \\
\hline & & \multirow{3}{*}{$\begin{array}{l}\text { Group } 1 \\
\text { Baseline }\end{array}$} & \multirow[t]{3}{*}{ Group 2} & \multirow{2}{*}{\multicolumn{2}{|c|}{$\frac{\text { Difference }^{a}}{\text { [Group 2- Group 1] }}$}} \\
\hline & & & & & \\
\hline & & & & Estimate & $p$-value \\
\hline \multicolumn{6}{|l|}{ Panel A } \\
\hline \multicolumn{6}{|l|}{ Woman's age } \\
\hline$<20$ years & $10,815(0.14)$ & $917(0.14)$ & $1137(0.15)$ & 0.014 & 0.581 \\
\hline 20-24 years & $33,999(0.45)$ & $3061(0.47)$ & $3292(0.45)$ & -0.022 & 0.512 \\
\hline 25-29 years & $21,236(0.28)$ & $1820(0.28)$ & $1941(0.26)$ & -0.015 & 0.561 \\
\hline$>=30$ years & $9516(0.13)$ & $735(0.11)$ & $996(0.14)$ & 0.023 & 0.620 \\
\hline \multicolumn{6}{|l|}{ Woman's schooling } \\
\hline No schooling & $6815(0.09)$ & $650(0.10)$ & $714(0.10)$ & -0.003 & 0.973 \\
\hline Some primary & $7637(0.10)$ & $694(0.11)$ & $734(0.10)$ & -0.007 & 0.864 \\
\hline Some lower secondary & $34,752(0.46)$ & $2886(0.44)$ & $3396(0.46)$ & 0.019 & 0.447 \\
\hline Some higher secondary & $16,421(0.22)$ & $1368(0.21)$ & $1563(0.21)$ & 0.003 & 0.938 \\
\hline Some college & $9941(0.13)$ & $934(0.14)$ & $958(0.13)$ & -0.013 & 0.756 \\
\hline \multicolumn{6}{|c|}{ Time taken to travel from home to hospital } \\
\hline$<2 \mathrm{~h}$ & $39,041(0.52)$ & $3972(0.61)$ & $3564(0.48)$ & -0.124 & 0.060 \\
\hline $2-6 h$ & $28,273(0.37)$ & $2150(0.33)$ & $2955(0.40)$ & 0.072 & 0.145 \\
\hline$>=6 \mathrm{~h}$ & $8252(0.11)$ & $411(0.06)$ & $847(0.11)$ & 0.052 & 0.055 \\
\hline \multicolumn{6}{|l|}{ Parity } \\
\hline 1 & $43,820(0.58)$ & $3771(0.58)$ & $4365(0.59)$ & 0.015 & 0.359 \\
\hline 2 & $24,112(0.32)$ & $2077(0.32)$ & $2251(0.31)$ & -0.012 & 0.463 \\
\hline $3 \&+$ & $7634(0.10)$ & $685(0.10)$ & $750(0.10)$ & -0.003 & 0.915 \\
\hline \multicolumn{6}{|l|}{ Ethnicity } \\
\hline Hill Brahmin & $16,329(0.22)$ & $1574(0.24)$ & $1357(0.18)$ & -0.057 & 0.543 \\
\hline Chhetri & $10,693(0.14)$ & $831(0.13)$ & $1223(0.17)$ & 0.039 & 0.364 \\
\hline Janajaati & $28,927(0.38)$ & $2135(0.33)$ & $3214(0.44)$ & 0.110 & 0.155 \\
\hline Madhesi & $4975(0.07)$ & $514(0.08)$ & $421(0.06)$ & -0.022 & 0.799 \\
\hline Dalit & $11,139(0.15)$ & $1200(0.18)$ & $803(0.11)$ & -0.075 & 0.157 \\
\hline Muslim & $2126(0.03)$ & $173(0.03)$ & $217(0.03)$ & 0.003 & 0.910 \\
\hline Others & $1378(0.02)$ & $106(0.02)$ & $131(0.02)$ & 0.002 & 0.838 \\
\hline \multicolumn{6}{|l|}{ Region } \\
\hline Terai & $53,459(0.71)$ & $3806(0.58)$ & $6114(0.83)$ & 0.247 & 0.596 \\
\hline Hill & $21,419(0.28)$ & $2709(0.41)$ & $1123(0.15)$ & -0.262 & 0.555 \\
\hline Mountain & $688(0.01)$ & $18(0.00)$ & $129(0.02)$ & 0.015 & 0.418 \\
\hline Had abortion(s) before & $3096(0.04)$ & $227(0.03)$ & $314(0.04)$ & 0.008 & 0.578 \\
\hline Male child born & $40,742(0.54)$ & $3528(0.54)$ & $4063(0.55)$ & 0.012 & 0.565 \\
\hline \multicolumn{6}{|l|}{ Panel B } \\
\hline Received Any FP counseling & $21,678(0.29)$ & $544(0.08)$ & $624(0.08)$ & 0.001 & 0.971 \\
\hline Received PPIUD counseling & $15,607(0.21)$ & $44(0.01)$ & $71(0.01)$ & 0.003 & 0.673 \\
\hline PPIUD uptake & $1685(0.02)$ & $3(0.00)$ & $1(0.00)$ & 0.000 & 0.338 \\
\hline Total women & 75,566 & 6533 & 7366 & & \\
\hline
\end{tabular}

${ }^{a}$ Significance of difference tested using wild cluster bootstrap method Proportion of each category in parenthesis 


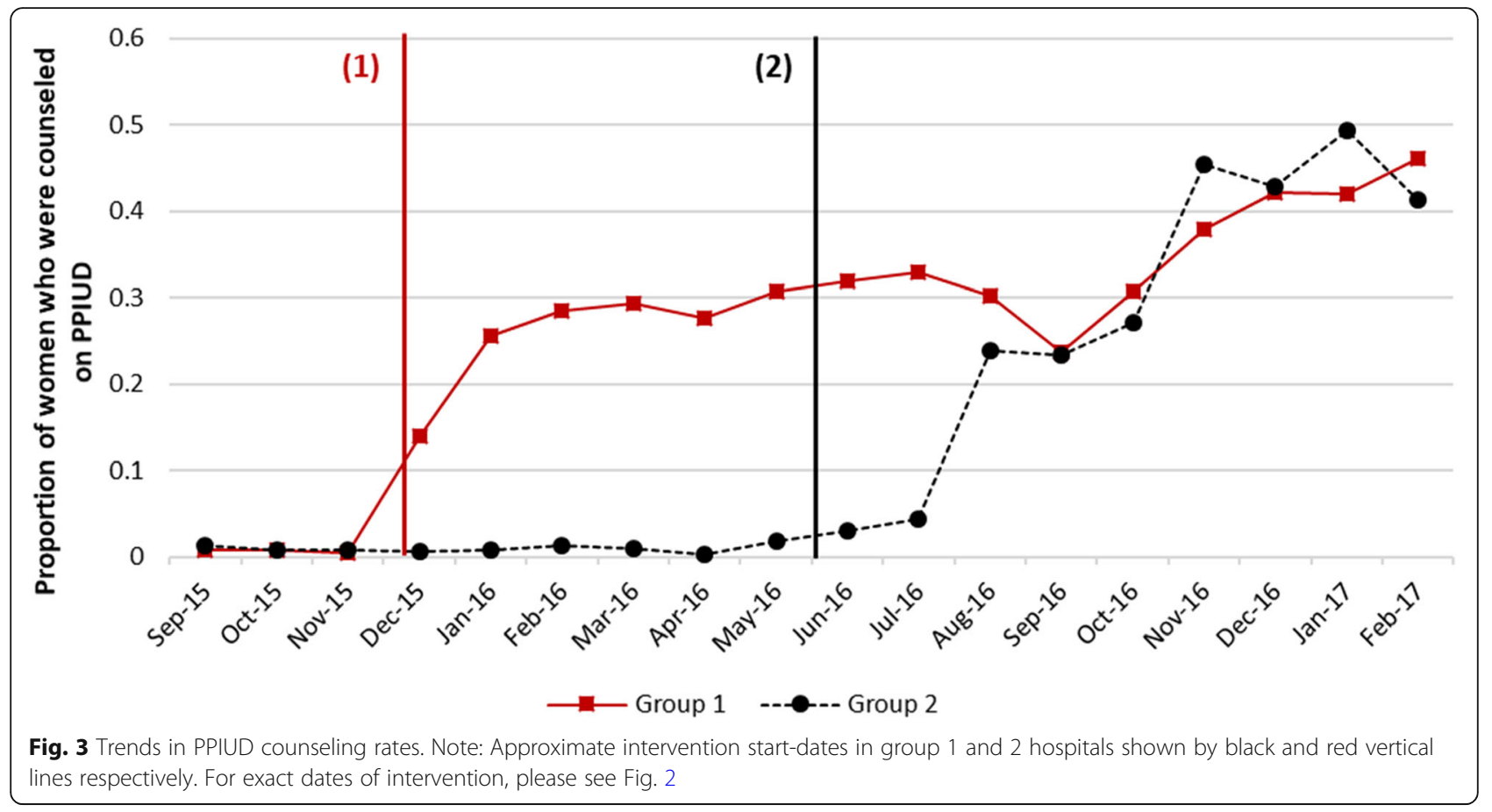

of providers and the start of the intervention, but shows a downward trend later.

Table 3 shows estimates of the effect of the intervention on PPIUD counseling in column 1 with the confidence interval in column 2 . The estimate in column 1 controls only for hospital and month fixed effects, and we include results with additional characteristics of the women and birth as controls in column 3 with confidence intervals of these estimates given in column 4 . On average, we find that the intervention increased the counseling rate by 25 pp. [95\%CI: 14-40 pp]. Our effect estimate for the intervention does not depend on the inclusion of the individual women level controls, which is expected since these do not change much between the baseline and intervention periods and are unlikely to explain the increase in the outcome variable between the two periods.

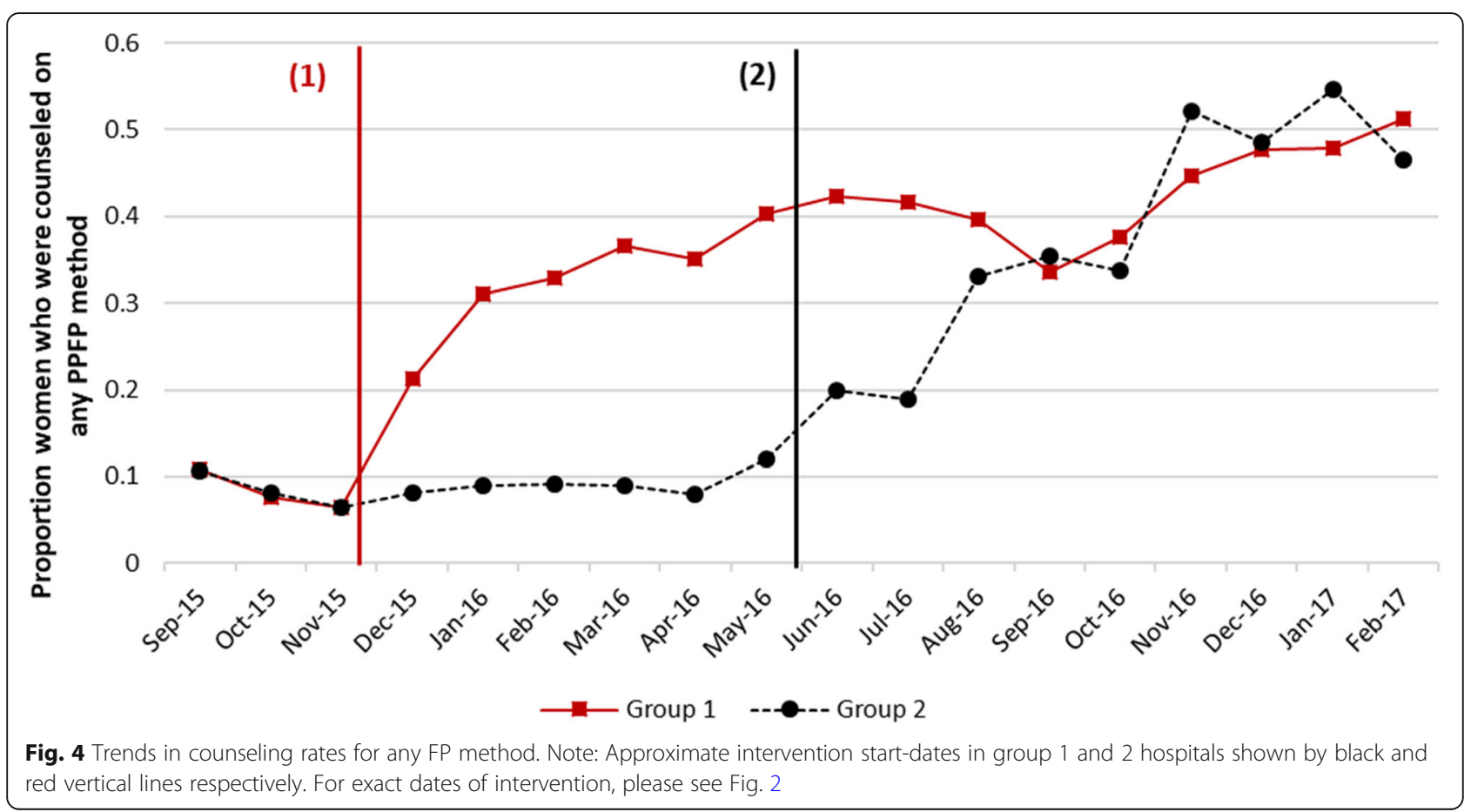


Table 2 Characteristics of PPIUD counseling and PPIUD knowledge if counseled

\begin{tabular}{ll}
\hline & $\mathrm{n}$ (prop.) \\
\hline Timing of PPIUD counseling & \\
Before admission, during ANC & $6124(0.392)$ \\
After admission only & $6644(0.426)$ \\
Both & $2838(0.182)$ \\
PPIUD knowledge & \\
can't recall any benefits/disadvantages, & $3775(0.244)$ \\
or recall disadvantages only & \\
recall any benefit(s) only & $8071(0.522)$ \\
recall both benefit(s) and disadvantage(s) & $3617(0.234)$ \\
Women given opportunity to ask questions & $7823(0.502)$ \\
Woman given a leaflet during counseling & $9012(0.578)$ \\
Total & 15,463 \\
\hline
\end{tabular}

While the intervention increased counseling rates overall, Table 3 shows that some subgroups of women were more likely to be counseled. Women aged 20-29 years of age and more educated women were more likely to receive PPIUD counseling. Madhesi and Muslim women were less likely to receive counseling, as were those who had long travel distances to the hospital. Counseling rates were higher among women with high parity, and among women who had previously had an abortion. The distance variable may reflect a lack of counseling in the hospital in the antenatal period and exposure to staff trained in antenatal PPIUD counseling. The other factors related to being counseled may reflect provider bias in the appropriateness of the method to certain women, or some types of women refusing counseling.

We also estimate variance inflation factor (VIF) of the adjusted model to test for multicollinearity, and find that there is some collinearity with a mean VIF of 2.16, and a VIF of 3.75 for the treatment variable in the first and the second model. We decided to keep the model structure for both models as this level of VIF is considered acceptable $(<5)$.

In Table 4 we report the results of a similar ITT model for the effect of the intervention on PPIUD uptake. We find the intervention increased PPIUD uptake by 4.4 pp. [95\%CI: 2.8-6.4 pp]. Again, the inclusion of the women level variables has little effect on our intervention effect estimate. Uptake varies across different groups of women, but this may reflect differences in counseling rates or difference in uptake conditional on being counseled.

The ITT estimates in Table 4 show the impact of the intervention on uptake of PPIUD. However, PPIUD counseling coverage was very incomplete even during the intervention period, and many more women might have accepted PPIUD if they had been counseled. We therefore wish to estimate the effect of being counseled on PPIUD uptake; this would give us an estimate of how successful the intervention could have been if all women had been counseled. A simple estimate of the effect of counseling on PPIUD uptake is likely to be biased if counseling was targeted by providers to focus on women more likely to accept PPIUD. Indeed, in Table 3 we see that counseling is correlated with the characteristics of

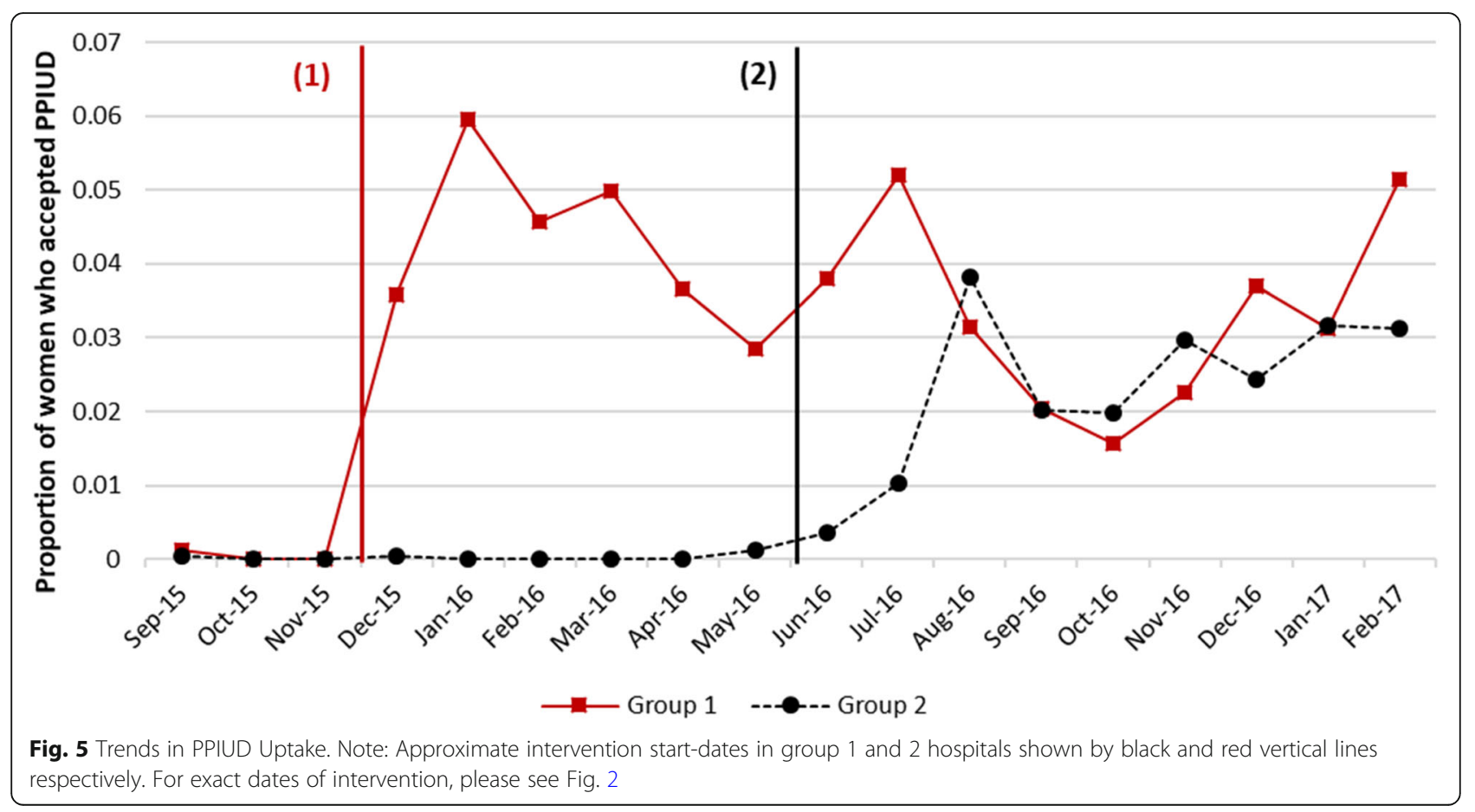


Table 3 Intent-to-Treat Effect of the intervention on PPIUD counseling

\begin{tabular}{|c|c|c|c|c|}
\hline & \multicolumn{4}{|c|}{ Dependent variable: Counseled on PPIUD } \\
\hline & Est. & $95 \% \mathrm{Cl}$ & Est. & $95 \% \mathrm{Cl}$ \\
\hline Post-treatment (Ref: Pre-treatment) & $0.251^{* *}$ & {$[0.136-0.402]$} & $0.251^{* *}$ & {$[0.142-0.400]$} \\
\hline \multicolumn{5}{|l|}{ Woman's age (Ref: < 20 years) } \\
\hline $20-24$ years & & & $0.017^{* *}$ & {$[0.002-0.036]$} \\
\hline $25-29$ years & & & $0.021^{* *}$ & {$[0.001-0.041]$} \\
\hline$>29$ years & & & 0.012 & {$[-0.017-0.045]$} \\
\hline \multicolumn{5}{|c|}{ Woman's schooling (Ref: No schooling) } \\
\hline Some primary & & & $0.028^{* *}$ & {$[0.003-0.045]$} \\
\hline Some lower secondary & & & $0.049^{* * *}$ & {$[0.031-0.063]$} \\
\hline Some higher secondary & & & $0.061^{* *}$ & [0.029-0.093] \\
\hline Some college or higher & & & $0.058^{* *}$ & {$[0.029-0.091]$} \\
\hline \multicolumn{5}{|c|}{ Time to travel from home to hospital (Ref: $<2 \mathrm{~h}$ ) } \\
\hline $2-6 h$ & & & $-0.056^{* *}$ & {$[-0.140--0.001]$} \\
\hline$>6 \mathrm{~h}$ & & & $-0.080^{*}$ & {$[-0.181-0.045]$} \\
\hline \multicolumn{5}{|l|}{ Parity (Ref: 1) } \\
\hline 2 & & & $0.056^{* * *}$ & {$[0.036-0.077]$} \\
\hline 3 or more & & & $0.086^{* * *}$ & {$[0.056-0.113]$} \\
\hline \multicolumn{5}{|l|}{ Ethnicity (Ref: Hill Brahmin) } \\
\hline Chhetri & & & 0.008 & {$[-0.027-0.026]$} \\
\hline Janajaati & & & -0.007 & {$[-0.047-0.022]$} \\
\hline Madhesi & & & $-0.053^{* *}$ & {$[-0.081--0.030]$} \\
\hline Dalit & & & -0.013 & {$[-0.030-0.003]$} \\
\hline Muslim & & & $-0.061^{* *}$ & {$[-0.110--0.023]$} \\
\hline Others & & & -0.008 & {$[-0.024-0.006]$} \\
\hline \multicolumn{5}{|l|}{ Region (Ref: Terai) } \\
\hline Hill & & & 0.0004 & {$[-0.075-0.109]$} \\
\hline Mountain & & & 0.037 & {$[-0.119-0.197]$} \\
\hline Had an abortion before & & & $0.015^{* *}$ & {$[0.003-0.047]$} \\
\hline Male child born & & & 0.002 & {$[-0.008-0.012]$} \\
\hline Constant & -0.030 & {$[-0.178-0.098]$} & $-0.088^{* *}$ & {$[-0.165--0.005]$} \\
\hline Observations & 75,566 & & 74,523 & \\
\hline R-squared & 0.219 & & 0.237 & \\
\hline
\end{tabular}

All regression models adjusted for hospital and month fixed effects Note: Difference from zero effect tested using wild cluster bootstrap method ${ }^{* * *} p<0.01,{ }^{* *} p<0.05,{ }^{*} p<0.1$

women that suggests some targeting of counseling may be occurring. If this is the case, extending counseling to additional women may have lower impact than in those already being counseled.

In order to avoid this problem of targeted counseling we estimate the "adherence-adjusted" effect of the intervention, the effect of the intervention on PPIUD among those counseled due purely to the intervention and not targeting. Formally, this is an instrumental variable estimate where we use the predicted probability of counseling from column 3 of Table 3 as the explanatory variable in a two-stage procedure [21]. The results in Table 5 show the effect of counseling on PPIUD uptake using this approach to remove the effect of targeting. The adherence-adjusted estimate implies that receiving counseling due to the intervention increases uptake of PPIUD by around 17 percentage points [95\% CI: $14-40 \mathrm{pp}$ ].

Table 6 shows the determinants of PPIUD uptake among women who were counseled. Women who were counseled in the hospital after admission for delivery were more likely to take up PPIUD. Our measures of the quality of counseling, in the form of having the 
Table 4 Intent-to-Treat Effect of the intervention on PPIUD uptake

\begin{tabular}{|c|c|c|c|c|}
\hline & \multicolumn{4}{|c|}{ Dependent variable: PPIUD uptake } \\
\hline & Est. & $95 \% \mathrm{Cl}$ & Est. & $95 \% \mathrm{Cl}$ \\
\hline Post-treatment (Ref: Pre-treatment) & $0.044^{* * *}$ & {$[0.027-0.064]$} & $0.044^{* * *}$ & {$[0.028-0.064]$} \\
\hline \multicolumn{5}{|l|}{ Woman's age (Ref: < 20 years) } \\
\hline 20-24 years & & & $-0.004^{*}$ & {$[-0.008-0.001]$} \\
\hline $25-29$ years & & & $-0.007^{* *}$ & {$[-0.010--0.004]$} \\
\hline$>29$ years & & & -0.001 & {$[-0.008-0.008]$} \\
\hline \multicolumn{5}{|c|}{ Woman's schooling (Ref: No schooling) } \\
\hline Some primary & & & 0.0004 & {$[-0.017-0.016]$} \\
\hline Some lower secondary & & & -0.002 & {$[-0.020-0.009]$} \\
\hline Some higher secondary & & & -0.003 & {$[-0.023-0.009]$} \\
\hline Some college & & & -0.003 & {$[-0.024-0.012]$} \\
\hline \multicolumn{5}{|c|}{ Time to travel from home to hospital (Ref: $<2 \mathrm{~h}$ ) } \\
\hline $2-6 h$ & & & 0.0006 & {$[-0.004-0.007]$} \\
\hline$>6 \mathrm{~h}$ & & & -0.001 & {$[-0.014-0.007]$} \\
\hline \multicolumn{5}{|l|}{ Parity (Ref: 1) } \\
\hline 2 & & & $0.022^{* *}$ & {$[0.012-0.034]$} \\
\hline 3 or more & & & $0.030^{* *}$ & [0.018-0.045] \\
\hline \multicolumn{5}{|l|}{ Ethnicity (Ref: Hill Brahmin) } \\
\hline Chhetri & & & $0.003^{*}$ & {$[0.000-0.007]$} \\
\hline Janajaati & & & $0.003^{* *}$ & {$[0.001-0.008]$} \\
\hline Madhesi & & & -0.002 & {$[-0.010-0.011]$} \\
\hline Dalit & & & 0.0001 & {$[-0.005-0.006]$} \\
\hline Muslim & & & $-0.010^{* *}$ & {$[-0.025--0.003]$} \\
\hline Others & & & 0.001 & {$[-0.007-0.010]$} \\
\hline \multicolumn{5}{|l|}{ Region (Ref: Terai) } \\
\hline Hill & & & -0.001 & {$[-0.010-0.011]$} \\
\hline Mountain & & & 0.0007 & {$[-0.016-0.018]$} \\
\hline Had an abortion before & & & $0.011^{* *}$ & {$[0.006-0.018]$} \\
\hline Male child born & & & $0.003^{* *}$ & {$[0.001-0.007]$} \\
\hline Constant & $-0.005^{* *}$ & {$[-0.014--0.001]$} & -0.013 & {$[-0.031-0.010]$} \\
\hline Observations & 75,566 & & 74,523 & \\
\hline R-squared & 0.017 & & 0.025 & \\
\hline
\end{tabular}

All regression models adjusted for hospital and month fixed effects Note: Difference from null tested using wild cluster bootstrap method ${ }^{* * *} p<0.01,{ }^{* *} p<0.05,{ }^{*} p<0.1$

opportunity to ask questions during counseling, and being able to remember benefits and disadvantages of PPIUD are correlated with a higher rate of PPIUD uptake. Being given a PPIUD information leaflet, however, did not seem to be related to uptake. Women with secondary or higher education are less likely to take up PPIUD, and Muslim women were less likely to choose PPIUD compared to Hill Brahmin women. PPIUD uptake was higher among women with more children, and those who wanted to space or limit their future pregnancies.

\section{Discussion}

The results from this study show that the intervention had a statistically significant impact on increasing PPIUD counseling rates and PPIUD uptake among women in the six study hospitals. We further find that the impact of the intervention on PPIUD uptake was about four times larger in women who were counseled.

However, we find that only a quarter of women were counseled on family planning, and furthermore, nearly one-third of those counseled were told of only one contraceptive method. In addition, a substantial number 
Table 5 Adherence-adjusted Impact of the Intervention_Impact of PPIUD counseling on PPIUD uptake

\begin{tabular}{|c|c|c|c|c|}
\hline & \multicolumn{4}{|c|}{ Dependent variable: PPIUD uptake } \\
\hline & Est. & $95 \% \mathrm{Cl}$ & Est. & $95 \% \mathrm{Cl}$ \\
\hline Counseled on PPIUD & $0.173^{* * *}$ & {$[0.098-0.246]$} & $0.174^{* * *}$ & {$[0.099-0.249]$} \\
\hline \multicolumn{5}{|l|}{ Woman's age (Ref: <20) } \\
\hline 20-24 years & & & $-0.006^{* *}$ & {$[-0.012--0.001]$} \\
\hline $25-29$ years & & & $-0.009^{* *}$ & {$[-0.014--0.004]$} \\
\hline$>29$ years & & & -0.002 & {$[-0.012-0.007]$} \\
\hline \multicolumn{5}{|c|}{ Woman's schooling (Ref: No schooling) } \\
\hline Some primary & & & -0.004 & {$[-0.014-0.011]$} \\
\hline Some lower secondary & & & $-0.009^{*}$ & {$[-0.023-0.001]$} \\
\hline Some higher secondary & & & $-0.013^{* *}$ & {$[-0.027--0.004]$} \\
\hline Some college & & & $-0.013^{* *}$ & {$[-0.028--0.003]$} \\
\hline \multicolumn{5}{|c|}{ Time to travel from home to hospital (Ref: $<2 \mathrm{~h}$ ) } \\
\hline $2-6 h$ & & & $0.010^{* *}$ & {$[0.001-0.022]$} \\
\hline$>6 \mathrm{~h}$ & & & $0.012^{* *}$ & {$[0.005-0.019]$} \\
\hline \multicolumn{5}{|l|}{ Parity (Ref: 1) } \\
\hline 2 & & & $0.013^{* *}$ & {$[0.004-0.021]$} \\
\hline 3 or more & & & $0.016^{* *}$ & {$[0.003-0.029]$} \\
\hline \multicolumn{5}{|l|}{ Ethnicity (Ref: Hill Brahmin) } \\
\hline Chhetri & & & 0.003 & {$[-0.003-0.011]$} \\
\hline Janajaati & & & $0.005^{*}$ & {$[0.000-0.013]$} \\
\hline Madhesi & & & 0.007 & {$[-0.002-0.018]$} \\
\hline Dalit & & & 0.002 & {$[-0.003-0.007]$} \\
\hline Muslim & & & 0.0003 & {$[-0.006-0.009]$} \\
\hline Others & & & 0.004 & {$[-0.007-0.020]$} \\
\hline \multicolumn{5}{|l|}{ Region (Ref: Terai) } \\
\hline Hill & & & -0.001 & {$[-0.007-0.001]$} \\
\hline Mountain & & & -0.007 & {$[-0.032-0.019]$} \\
\hline Had an abortion before & & & $0.010^{* *}$ & {$[0.005-0.018]$} \\
\hline Male child born & & & $0.002^{* * *}$ & {$[0.001-0.004]$} \\
\hline Constant & -0.0006 & {$[-0.023-0.023]$} & -0.0003 & {$[-0.024-0.024]$} \\
\hline Observations & 75,566 & & 74,525 & \\
\hline R-squared & 0.053 & & 0.058 & \\
\hline
\end{tabular}

All regression models adjusted for hospital and month fixed effects Note: Difference from null tested using wild cluster bootstrap method. Second Stage Results Shown. First Stage results in Table 3, Columns (1) and (2) ${ }^{* * *} p<0.01,{ }^{* *} p<0.05,{ }^{*} p<0.1$

of women were only counseled after admission to the hospital for delivery, rather than in the antenatal period. The intervention focused on training in the hospital delivery wards and their antenatal care facilities and many women, particularly those living far from a hospital, may have had their antenatal care elsewhere. There is substantial variation in counseling rates between different groups of women which may reflect access to hospital-based antenatal services but which may also reflect provider bias in the appropriateness of the method for different groups.
Quality of care is a critical factor that determines service uptake and method continuation. We found that patients who were likely offered higher quality care (women counseled on both benefits and disadvantages of the method) were more likely to take up PPIUD as compared to women offered lower quality care (women who only knew benefits or disadvantages). A paper that examined adverse effects of PPIUD insertion across six countries where this intervention was implemented found $22 \%$ of women with PPIUD reporting at least one adverse effect at 6 -week follow-up, with $6.9 \%$ reporting vaginal 
Table 6 Determinants of PPIUD uptake among women who were counseled

\begin{tabular}{|c|c|c|}
\hline & \multicolumn{2}{|c|}{$\begin{array}{l}\text { Dependent variable: } \\
\text { PPIUD uptake }\end{array}$} \\
\hline & Est. & $95 \% \mathrm{Cl}$ \\
\hline Woman given a leaflet during counseling & -0.008 & {$[-0.050-0.053]$} \\
\hline \multicolumn{3}{|c|}{$\begin{array}{l}\text { PPIUD Knowledge (Ref: Women can't recall any benefits/disadvantages, } \\
\text { or disadvantages only) }\end{array}$} \\
\hline recall benefit(s) only & $0.054^{* *}$ & {$[0.026-0.080]$} \\
\hline recall both benefit(s) and disadvantage(s) & $0.122^{* * *}$ & {$[0.091-0.198]$} \\
\hline Women given opportunity to ask questions & $0.043^{* *}$ & {$[0.012-0.095]$} \\
\hline \multicolumn{3}{|c|}{ Timing of PPIUD Counseling (Ref: Before Admission, during ANC) } \\
\hline After Admission Only & $0.144^{* *}$ & {$[0.096-0.237]$} \\
\hline Both & $0.093^{* *}$ & {$[0.055-0.187]$} \\
\hline \multicolumn{3}{|l|}{ Woman's Age (Ref: < 20) } \\
\hline $20-24$ years & $-0.020^{* *}$ & {$[-0.036-0.000]$} \\
\hline 25-29 years & $-0.036^{* *}$ & {$[-0.045--0.027]$} \\
\hline$>29$ years & -0.015 & {$[-0.035-0.037]$} \\
\hline \multicolumn{3}{|l|}{ Woman's Schooling (Ref: No schooling) } \\
\hline Some Primary & -0.015 & {$[-0.054-0.070]$} \\
\hline Some Lower Secondary & -0.042 & {$[-0.072-0.013]$} \\
\hline Some Higher Secondary & -0.045 & {$[-0.072-0.011]$} \\
\hline Some College & $-0.051^{*}$ & {$[-0.083-0.012]$} \\
\hline \multicolumn{3}{|l|}{ Time to travel from home to hospital (Ref: $<2 \mathrm{~h}$ ) } \\
\hline $2-6 h$ & 0.008 & {$[-0.011-0.038]$} \\
\hline$>6 \mathrm{~h}$ & -0.0027 & {$[-0.046-0.074]$} \\
\hline \multicolumn{3}{|l|}{ Parity (Ref: 1) } \\
\hline 2 & $0.039^{* *}$ & {$[0.011-0.055]$} \\
\hline 3 or more & $0.050^{*}$ & {$[-0.003-0.076]$} \\
\hline \multicolumn{3}{|l|}{ Ethnicity (Ref: Hill Brahmin) } \\
\hline Chhetri & 0.007 & {$[-0.010-0.029]$} \\
\hline Janajaati & 0.010 & {$[-0.004-0.036]$} \\
\hline Madhesi & -0.003 & {$[-0.041-0.107]$} \\
\hline Dalit & -0.002 & {$[-0.026-0.034]$} \\
\hline Muslim & $-0.035^{*}$ & {$[-0.061-0.003]$} \\
\hline Others & 0.003 & {$[-0.042-0.048]$} \\
\hline \multicolumn{3}{|l|}{ Region (Ref: Terai) } \\
\hline Hill & -0.008 & {$[-0.057-0.049]$} \\
\hline Mountain & 0.017 & {$[-0.145-0.144]$} \\
\hline Had an abortion before & $0.025^{*}$ & {$[-0.006-0.042]$} \\
\hline Male child born & $0.014^{* * *}$ & {$[0.006-0.027]$} \\
\hline \multicolumn{3}{|c|}{ Future Fertility Preference (Ref: Unsure about Limiting) } \\
\hline Want to Space & $0.023^{* *}$ & {$[0.006-0.054]$} \\
\hline Want to Limit & $0.020^{* * *}$ & {$[0.006-0.049]$} \\
\hline Undecided on Spacing & -0.006 & {$[-0.060-0.017]$} \\
\hline Can't get Pregnant & $-0.119^{* *}$ & {$[-0.240--0.053]$} \\
\hline Refused/Other & $-0.068^{* *}$ & {$[-0.182--0.003]$} \\
\hline
\end{tabular}

Table 6 Determinants of PPIUD uptake among women who were counseled (Continued)

\begin{tabular}{ll}
\hline & \multicolumn{2}{l}{$\begin{array}{l}\text { Dependent variable: } \\
\text { PPIUD uptake }\end{array}$} \\
\cline { 2 - 2 } & Est. $\quad 95 \% \mathrm{Cl}$ \\
\hline Constant & $-0.181 \quad[-0.379-0.021]$ \\
Observations & 15,241 \\
R-squared & 0.132 \\
\hline
\end{tabular}

All regression models adjusted for hospital and month fixed effects Note: Difference from null tested using wild cluster bootstrap method ${ }^{* * *} p<0.01,{ }^{* *} p<0.05,{ }^{*} p<0.1$

discharge, $4.4 \%$ abdominal pain, and 2.4\% irregular bleeding [26]. The same study reported expulsion rate of $3.9 \%$ by 6 weeks since PPIUD insertion in Nepal, as compared to a minimum of $1.2 \%$ in Tanzania and $4.3 \%$ in Kenya, and a removal rate of $7.4 \%$ in Nepal as compared to $2.6 \%$ in Kenya and $8.3 \%$ in Tanzania. Note that for the study above, the 6-week follow-up rate for Nepal was the highest at $84 \%$, and was between (42-54) \% for the remaining five countries indicating that the expulsion and removal data were more complete for Nepal than for the other countries. The high removal rate by women in Nepal suggests a need for improvement in quality of counseling. This may also reflect dynamics of an economy based on large number of Nepalese men working abroad where women often decide on contraceptive methods alone, and husbands, when they come back for short periods of time are not satisfied with the method as they do not receive any information or counseling on the method. These results suggest a need for modified counseling approach in Nepal catered to country-specific labor and household power dynamics.

Another aspect of quality of care is the health system readiness and provider's capacity to deliver care. A paper examining provider perspectives on the FIGO-NESOG intervention in Nepal finds that the providers in the study hospitals were positive about implementing PPFP counseling and PPIUD insertion services as a part of routine maternity care, but identified several supply-side issues preventing them from providing high-quality care including: (1) shortage of human resources, (2) lack of supplies and (3) lack of support from the hospital management [27]. Hence, improvements in health systems readiness to deliver these services would not only improve provider morale, but could also improve counseling rates and method uptake.

Among those counseled, women who expressed their desire to limit or space their future pregnancies were more likely to take up PPIUD compared to women who were unsure about limiting. As older women and women with higher parity are more likely to want to space or limit their future pregnancies [28], higher PPIUD uptake by older women, women with high parity births, or history 
of abortion might mean that the intervention enabled women to meet their unmet need for family planning. This heterogeneity implies that these sub-populations might be prioritized by policymakers during scale-up to reach populations with the highest demand for postpartum contraception.

The main analytical strategy of the study was to examine the intent-to-treat effect, and the impact on those who were actually treated (that is, who were counseled). However, there is also some heterogeneity in fidelity to the intervention across the different hospital sites, where counseling rates at some hospitals in some months were as high as $67 \%$. Examining key factors behind this heterogeneous uptake of the intervention at the hospital and even at the provider level is an important area of future research.

The women in our study are not nationally representative. On average, they are younger and have more years of schooling than women of reproductive age in Nepal [8]. In targeting tertiary hospitals with high obstetric caseloads, our study excludes women who delivered at home, or in smaller primary health care centers. The implementation design also does not include adolescent girls who also have a high unmet need for contraception primarily to delay age at first childbirth [29, 30]. By design, the study was implemented in large tertiary hospitals but in many rural areas, births either take place in lower level district hospitals, primary health centers or health posts, and it is unclear if the intervention could be implemented in these smaller facilities. Implications on program resources including costs and logistics to expand PPFP and PPIUD services to the numerous district hospitals, and other health facilities need to be weighed against the benefits of expanded reach to women who often have even more limited access to postpartum family planning, and might benefit more from a long-acting and reversible method given higher time, cost and distance barriers to seeking care from health facilities.

High unmet need of postpartum family planning, and contraceptive prevalence rate that has only moved from 48 to $52.6 \%$ in the last decade (2006 to 2016 ) requires that the public health system in Nepal be introduced to innovative reproductive health interventions to ensure universal access to high-quality reproductive and sexual health services. This study aimed to understand the feasibility of one such innovation, which was the attempt to integrate postpartum family planning counseling and PPIUD insertion service provision into routine maternity care services in Nepal. Our evaluation demonstrates that incorporating PPIUD services into routine maternity care is feasible, and there is a demand for the PPIUD from women who have need for spacing or limiting their births. The intervention had a reasonable impact on PPIUD counseling rates, though it fell well short of full coverage of women delivering in the intervention hospitals, and a smaller, but statistically significant impact on PPIUD uptake, particularly among those who received high-quality counseling. We conclude that the intervention had a positive impact though its effectiveness might be improved by expanding the coverage of counseling and ensuring that the counseling is of high quality.

\section{Conclusions}

The intervention designed and implemented by FIGO and NESOG increased PPIUD counseling rates and PPIUD uptake among women, especially among older women, those with high parity, and those who received better quality counseling. Had the counseling covered all women who gave birth, PPIUD uptake would have been four times higher. Our results suggest that the program impact could be improved further by: (1) expanding the coverage of PPFP counseling during antenatal care, and (2) improving quality of counseling. Increasing the coverage of high-quality counseling will likely require increased human resources for health and a shift in emphasis to counseling during the antenatal period in health centers providing antenatal care and not just in hospital antenatal clinics.

\section{Abbreviations \\ ANC: Antenatal Care; BPKIHS: BP Koirala Institute of Health Sciences; $\mathrm{Cl}$ : Confidence Interval; FIGO: International Federation of Obstetricians and Gynaecologists; ICPD: International Conference on Population and Development; ITT: Intention-To-Treat; IUD: Intra-Uterine Device; NESOG: Nepal Society of Obstetricians and Gynaecologists; PNC: Postnatal Care; PP: Percentage Point; PPIUD: Postpartum Intra-Uterine Device; VIF: Variance Inflation Factor; WHO: World Health Organization}

\section{Acknowledgements}

We gratefully acknowledge the advice and support generously extended by Sir Sabaratnam Arulkumaran. The facility coordinators in the six study hospitals were critical for the implementation of the study. We are especially grateful to all study participants who kindly responded to questions by the interviewers.

\section{Funding}

The funding for the study was provided by the Susan Thompson Buffett Foundation. The funding body played no role in the design of the study and collection, analysis, and interpretation of data or in writing the manuscript.

Availability of data and materials

Data and materials from the study may be available upon request from the Center for Research on Environment, Health and Population Activities, Kusunti, Lalitpur, P.O. Box 9626, Kathmandu, Nepal.

\section{Authors' contributions}

All authors participated and contributed in developing the study and manuscript. EP and DC were responsible for conducting the main statistical analysis, conducting literature review, drafting and reviewing the main text; IS, DC, EP, MP, ErP, KT, and PC contributed to the conceptualization, design, and implementation of the study and assisted in finalizing the manuscript; MM and DM supervised data collection and preliminary analysis; and LB and GS assisted with the conduct of the study and data collection. All authors have read and approved the final manuscript and are aware that manuscript is being submitted to the journal. The findings, interpretations, and conclusions expressed in this paper are entirely those of the authors. They do not necessarily represent the views of the organizations with whom the authors are affiliated. 


\section{Ethics approval and consent to participate}

Ethical approval for this study was obtained through Nepal Health Research Council. The Harvard T. H Chan School of Public Health Office of Human Research Administration granted exempt status to the study as Harvard only received de-identified data. All women were first informed of the purpose of the study and what their participation may entail before seeking their consent. Only women who consented to participate were interviewed and included in this study.

\section{Consent for publication}

Not applicable.

\section{Competing interests}

We have read and understood the Reproductive Health policy on declaration of interests and declare that we have no competing interests.

\section{Publisher's Note}

Springer Nature remains neutral with regard to jurisdictional claims in published maps and institutional affiliations.

\section{Author details}

'The World Bank Group, 1818 H Street NW, Washington, DC 20433, USA. 2Department of Global Health and Population, Harvard T. H. Chan School of Public Health, 665 Huntington Avenue, Boston, MA 02115, USA. ${ }^{3}$ Center for Research on Environment, Health and Population Activities (CREHPA), Kusunti, Lalitpur, P.O. Box 9626, Kathmandu, Nepal. ${ }^{4}$ Ipas, P. O. Box 9990, Chapel Hill, NC 27515, USA. ${ }^{5}$ Nepal Society of Obstetricians and Gynaecologists (NESOG), Paropakar Maternity \& Women's Hospital, Thapathali, Kathmandu 23700, Nepal. ${ }^{6}$ Ministry of Health and Population, Kathmandu, Nepal.

Received: 9 May 2018 Accepted: 15 May 2019

Published online: 29 May 2019

\section{References}

1. Cleland J, Conde-Agudelo A, Peterson H, Ross J, Tsui A. Contraception and health. Lancet. 2012 Jul 20;380(9837):149-56.

2. Cleland J, Bernstein S, Ezeh A, Faundes A, Glasier A, Innis J. Family planning: the unfinished agenda. Lancet. 2006;368(9549):1810-27.

3. Rutstein SO. Effects of preceding birth intervals on neonatal, infant and under-five years mortality and nutritional status in developing countries: evidence from the demographic and health surveys. Int J Gynecol Obstet. 2005;89:S7-24.

4. Kozuki N, Walker N. Exploring the association between short/long preceding birth intervals and child mortality: using reference birth interval children of the same mother as comparison. BMC Public Health. 2013;13(Suppl 3):S6.

5. UNFPA. Programme of action of the United Nations international conference on population and development. Cairo: UN; 1994.

6. Cohen SA, Richards CL. The Cairo consensus: population, development and women. Fam Plan Perspect. 1994:26(6):272-7.

7. Alkema L, Kantorova V, Menozzi C, Biddlecom A. National, regional, and global rates and trends in contraceptive prevalence and unmet need for family planning between 1990 and 2015: a systematic and comprehensive analysis. Lancet. 2013 17;381(9878):1642-52.

8. Ministry of Health, Nepal, New ERA, ICF. Nepal Demographic and Health Survey 2016. Kathmandu, Nepal: Ministry of Health, Nepal; 2017. Available from: https://www.dhsprogram.com/pubs/pdf/fr336/fr336.pdf.

9. World Health Organization. Report of a WHO technical consultation on birth spacing, 2005. Geneva: World Health Organization; 2007.

10. Ministry of Health and Population (MOHP) [Nepal], New ERA, and Macro International Inc. Nepal Demographic and Health Survey 2011. Kathmandu, Nepal: Ministry of Health and Population, New ERA, and Macro International Inc.; 2012.

11. Stanton C, Blanc AK, Croft T, Choi Y. Skilled care at birth in the developing world: progress to date and strategies for expanding coverage. J Biosoc Sci. 2007;39(1):109-20.

12. Ministry of Health [Nepal], New ERA, ORC Macro. Nepal Demographic and Health Survey 2001. Calverton, Maryland, USA: Family Health Division, Ministry of Health; New ERA; and ORC Macro; 2002.

13. Pfitzer A, Mackenzie D, Blanchard H, Hyjazi $Y$, Kumar S, Kassa SL, et al. A facility birth can be the time to start family planning: postpartum intrauterine device experiences from six countries. Int J Gynecol Obstet. 2015;130:S54-61.

14. Kapp N, Curtis KM. Intrauterine device insertion during the postpartum period: a systematic review. Contraception. 2009;80(4):327-36.

15. World Health Organization. Programming strategies for postpartum family planning [Internet]. Geneva, Switzerland: World Health Organization; 2013 [cited 2016 Dec 21]. Available from: http://apps.who.int/iris/handle/ $10665 / 93680$

16. Lopez LM, Bernholc A, Hubacher D, Stuart G, Van Vliet HA. Immediate postpartum insertion of intrauterine device for contraception. In: Cochrane database of systematic reviews [internet]. John Wiley \& Sons, Ltd; 2015 [cited 2016 Dec 22]. Available from: http://onlinelibrary.wiley.com/ doi/10.1002/14651858.CD003036.pub3/abstract

17. McPake B, Witter S, Ensor T, Fustukian S, Newlands D, Martineau T, et al. Removing financial barriers to access reproductive, maternal and newborn health services: the challenges and policy implications for human resources for health. Hum Resour Health. 2013;11:46.

18. Karra M, Canning D, Foster $\mathrm{S}$, Shah $\mathrm{IH}$, Senanayake $H$, Ratnasiri UDP, et al. Location and content of counselling and acceptance of postpartum IUD in Sri Lanka. Reprod Health. 2017;14(14):42.

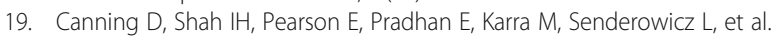
Institutionalizing postpartum intrauterine device (IUD) services in Sri Lanka, Tanzania, and Nepal: study protocol for a cluster-randomized steppedwedge trial. BMC Pregnancy Childbirth. 2016;16:362.

20. Clarke PS, Palmer TM, Windmeijer F. Estimating structural mean models with multiple instrumental variables using the generalised method of moments. Stat Sci. 2015 Feb;30(1):96-117.

21. Hernán MA, Hernández-Díaz S. Beyond the intention-to-treat in comparative effectiveness research. Clin Trials. 2012;9(1):48-55.

22. Bertrand M, Duflo E, Mullainathan S. How much should we trust differencesin-differences estimates? O J Econ. 2004:119(1):249-75.

23. Cameron AC, Gelbach JB, Miller DL. Bootstrap-based improvements for inference with clustered errors. Rev Econ Stat. 2008:90(3):414-27.

24. Webb MD. Reworking wild bootstrap based inference for clustered errors [internet]. Queen's University, Department of Economics; 2014 [cited 2016 Dec 16]. Report No.: 1315. Available from: https://ideas.repec.org/p/qed/ wpaper/1315.html.

25. Roodman D. BOOTTEST: Stata module to provide fast execution of the wild bootstrap with null imposed [Internet]. Boston College Department of Economics; 2016 [cited 2016 Dec 16]. (Statistical Software Components). Available from: https://ideas.repec.org/c/boc/bocode/s458121.html

26. Makins A, Taghinejadi N, Sethi M, Machiyama K, Munganyizi P, Odongo E, et al. FIGO postpartum intrauterine device initiative: complication rates across six countries. Int J Gynecol Obstet. 2018;143(S1):20-7.

27. Puri MC, Maharjan M, Pearson E, Pradhan E, Dhungel Y, Khadka A, et al. Delivering postpartum family planning services in Nepal: are providers supportive? BMC Health Serv Res. 2018;18(1):948

28. Lith LMV, Yahner M, Bakamjian L. Women's growing desire to limit births in sub-Saharan Africa: meeting the challenge. Glob Health Sci Pract. 2013;1(1):97-107.

29. Shah $\mathbb{H}$, Åhman E. Unsafe abortion differentials in 2008 by age and developing country region: high burden among young women. Reprod Health Matters. 2012;20(39):169-73.

30. Darroch JE, Woog V, Bankole A, Ashford L. Adding it up: costs and benefits of meeting the contraceptive needs of adolescents. [Internet]. Guttmacher Institute; 2016 [cited 2016 Dec 21]. Available from: http://www.popline.org/ node/649435

Ready to submit your research? Choose BMC and benefit from:

- fast, convenient online submission

- thorough peer review by experienced researchers in your field

- rapid publication on acceptance

- support for research data, including large and complex data types

- gold Open Access which fosters wider collaboration and increased citations

- maximum visibility for your research: over $100 \mathrm{M}$ website views per year

At $\mathrm{BMC}$, research is always in progress.

Learn more biomedcentral.com/submissions 